\title{
Medications that reduce emergency hospital admissions: an overview of systematic reviews and prioritisation of treatments
}

Niklas Bobrovitz ${ }^{1,2^{*}}$ D, Carl Heneghan ${ }^{1,2}$, Igho Onakpoya ${ }^{1,2}$, Benjamin Fletcher ${ }^{1}$, Dylan Collins ${ }^{1,3}$, Alice Tompson ${ }^{1,4}$, Joseph Lee', David Nunan ${ }^{1,2}$, Rebecca Fisher ${ }^{1,5}$, Brittney Scott ${ }^{6,7}$, Jack O'Sullivan ${ }^{1,2}$, Oliver Van Hecke',

Brian D. Nicholson ${ }^{1}$, Sarah Stevens ${ }^{1}$, Nia Roberts ${ }^{8}$ and Kamal R. Mahtani ${ }^{1,2}$

\begin{abstract}
Background: Rates of emergency hospitalisations are increasing in many countries, leading to disruption in the quality of care and increases in cost. Therefore, identifying strategies to reduce emergency admission rates is a key priority. There have been large-scale evidence reviews to address this issue; however, there have been no reviews of medication therapies, which have the potential to reduce the use of emergency health-care services. The objectives of this study were to review systematically the evidence to identify medications that affect emergency hospital admissions and prioritise therapies for quality measurement and improvement.
\end{abstract}

Methods: This was a systematic review of systematic reviews. We searched MEDLINE, PubMed, the Cochrane Database of Systematic Reviews \& Database of Abstracts of Reviews of Effects, Google Scholar and the websites of ten major funding agencies and health charities, using broad search criteria. We included systematic reviews of randomised controlled trials that examined the effect of any medication on emergency hospital admissions among adults. We assessed the quality of reviews using AMSTAR. To prioritise therapies, we assessed the quality of trial evidence underpinning meta-analysed effect estimates and cross-referenced the evidence with clinical guidelines.

Results: We identified 140 systematic reviews, which included 1968 unique randomised controlled trials and 925,364 patients. Reviews contained 100 medications tested in 47 populations. We identified high-to moderate-quality evidence for 28 medications that reduced admissions. Of these medications, 11 were supported by clinical guidelines in the United States, the United Kingdom and Europe. These 11 therapies were for patients with heart failure (angiotensin-convertingenzyme inhibitors, angiotensin II receptor blockers, aldosterone receptor antagonists and digoxin), stable coronary artery disease (intensive statin therapy), asthma exacerbations (early inhaled corticosteroids in the emergency department and anticholinergics), chronic obstructive pulmonary disease (long-acting muscarinic antagonists and long-acting beta-2 adrenoceptor agonists) and schizophrenia (second-generation antipsychotics and depot/maintenance antipsychotics).

\footnotetext{
* Correspondence: niklas.bobrovitz@phc.ox.ac.uk

${ }^{1}$ Nuffield Department of Primary Care Health Sciences, University of Oxford,

Radcliffe Observatory Quarter, Woodstock Road, Oxford OX2 6GG, United

Kingdom

${ }^{2}$ Centre for Evidence-Based Medicine, University of Oxford, Oxford, United

Kingdom

Full list of author information is available at the end of the article
}

(c) The Author(s). 2018 Open Access This article is distributed under the terms of the Creative Commons Attribution 4.0 International License (http://creativecommons.org/licenses/by/4.0/), which permits unrestricted use, distribution, and reproduction in any medium, provided you give appropriate credit to the original author(s) and the source, provide a link to the Creative Commons license, and indicate if changes were made. The Creative Commons Public Domain Dedication waiver (http://creativecommons.org/publicdomain/zero/1.0/) applies to the data made available in this article, unless otherwise stated. 
(Continued from previous page)

Conclusions: We identified 11 medications supported by strong evidence and clinical guidelines that could be considered in quality monitoring and improvement strategies to help reduce emergency hospital admission rates. The findings are relevant to health systems with a large burden of chronic disease and those managing increasing pressures on acute health-care services.

Keywords: Hospital admissions, Unplanned admissions, Emergency admissions, Unscheduled admissions, Pharmacology, Medication, Drug, Systematic review, Overview, Clinical guidelines

\section{Background}

Emergency hospital admissions place a major burden on patients and health-care systems. Large increases in emergency admissions can cause delays and cancellations of elective procedures, prolong emergency department waiting times and increase the risk of hospital-acquired infections [1-5]. Emergency admissions, which comprise 10\% of the total health-care budget in some countries, also have significant financial effects [6, 7]. Rates of emergency hospital admissions are rising in many countries, creating emergency-care crises $[6,8,9]$.

Identifying interventions that reduce emergency hospital admissions is, therefore, a priority for health services globally, and there have been large-scale evidence reviews to address this [10, 11]. However, a major gap in these systematic assessments has been the omission of medication therapy, which has the potential to reduce use of emergency health-care services. For example, a systematic review of randomised controlled trials (RCTs) has shown that aldosterone receptor antagonists reduce emergency admissions for heart failure by $21 \%$ over 20 months [12]. Despite these robust data, there have been no comprehensive reviews to identify and compare medications that effectively and safely prevent hospital admissions in different patient populations. Systematically identifying these beneficial medications is the first step towards monitoring and improving their use in practice. Given that there are existing mechanisms for quality measurement and improvement of clinical practices in many health systems, monitoring and improving medication use may be a feasible and efficient strategy to alleviate some of the burden of emergency admissions compared with the lengthy and expensive process of developing, testing and implementing new complex interventions.

The objectives of this study were to review systematically the evidence to identify medications that affect hospital admissions and prioritise therapies for quality improvement by assessing the quality of evidence and cross-referencing the findings with clinical guidelines.

\section{Methods}

\section{Protocol and registration}

We developed the methods using guidance on systematic reviews and overviews described in the Cochrane Handbook of Systematic Reviews of Interventions [13]. The protocol was registered (PROSPERO: CRD42014014779) [14] and published [15]. In our protocol, we specified that we would search for any type of intervention. This overview focuses on medications. Our subsequent overviews will describe the evidence for other types of interventions.

\section{Types of reviews}

We included systematic reviews of RCTs published in English that examined the effect of any medication on emergency hospital admissions in adults (16 years or older). We included reviews that searched two or more electronic databases and assessed and reported the quality of included studies. We defined a medication as any administered chemical or biological product. We included only reviews that reported at least one meta-analysed effect estimate for emergency hospital admissions that was not part of a composite measure. We defined an emergency hospital admission as an unanticipated admission or readmission to hospital that occurred at short notice because of a perceived need for immediate health care [16]. We did not consider admission to an emergency department or an observational unit to be a hospital admission. We excluded studies reporting only scheduled or elective hospital admissions. We excluded superseded Cochrane reviews. We excluded non-Cochrane reviews if all the RCT data on hospital admissions were included in a more recent review of the same intervention and patients. When two reviews reported identical clinical trial data, we selected the review that reported more detailed information, as judged by two of the authors through discussion and consensus (NB and IO).

\section{Search strategy and study selection}

We searched MEDLINE (OvidSP), PubMed, the Cochrane Database of Systematic Reviews \& Database of Abstracts of Reviews of Effects, Google Scholar and the websites of ten national funding agencies and health charities, using broad search criteria from inception to February 2016. The search strategy was developed by a library and information scientist (NR). The websites of national funding agencies and health charities were identified using Google searches and by our academic-clinician co-authors. We also contacted experts in emergency admissions and 
reviewed the reference lists of included reviews to identify additional studies. Details of the search can be found in Additional file 1: Table S1 in the online supplement. Three authors (NB, IO and BF) independently screened titles, abstracts and full-text articles for inclusion. Discrepancies in article inclusion were resolved by discussion. Inter-rater reliability for agreement between authors for title/abstract screening and full-text screening was quantified using Cohen's kappa statistic .

\section{Data extraction and quality assessment of reviews}

In pairs, we independently extracted information in duplicate on the characteristics of the reviews and assessed their quality using the Assessing the Methodological Quality of Systematic Reviews (AMSTAR) tool [17]. We have provided summary AMSTAR scores when describing review characteristics to give a broad indication of quality; however, full results are also provided as summary scores may obscure important strengths or weaknesses [17]. One minor revision to the AMSTAR tool was made: for item 2 (was there duplicate study selection and data extraction?) reviews did not score 'yes' if data selection or extraction was done by one reviewer and checked by another. Information on specific treatment comparisons in the reviews was extracted by one author (NB) and verified by a second (IO, BF, DC, AT, JL, RF, DN, BS, JO, OH, BN or SS). Discrepancies in extracted information or quality assessment scores were resolved by discussion. All reviews and each extracted treatment comparison were assigned a unique identifying number (e.g. review 100 or comparisons 100a and 100b).

Prioritising therapies through quality assessment of metaanalysed effect estimates and cross-referencing treatments with clinical guidelines

We assessed the quality of meta-analysed effect estimates showing statistically significant effects on admissions. We used criteria from the Grading of Recommendations Assessment, Development and Evaluation (GRADE) Working Group [18]. Using these ratings, we prioritised therapies based on the strength of their evidence base. Quality assessments were completed by one reviewer (NB) and verified by a second (DN). Two generalist clinicians (JL and IO) provided judgements for the indirectness domain, which included assessments of the comparability of populations, interventions, comparators and outcomes between studies and of the applicability of the body of studies to the aims of this overview.

A minimal important threshold in effect had to be defined to utilise the GRADE method, specifically, the imprecision domain [18]. To our knowledge, there is no consensus on what defines a minimal important threshold for hospital admissions. The goal of this research is to manage rising rates of emergency hospital admissions; therefore, we picked a threshold that would achieve this: a 3\% relative risk reduction. This threshold is equivalent to the population-adjusted average year-on-year increase in admissions in the UK over the past five years (2011-2016) $[9,19]$. The UK is facing the worst emergency-care crisis of any high- or middle-income country that we are aware of. If we were able to identify and implement interventions for every patient group that reduced admission rates by $3 \%$, then the overall admissions rate would cease to rise in the UK. In countries where annual increases are less than $3 \%$, which includes most other high- and middle-income countries facing emergency-care pressures, these interventions would operate to reduce the annual rate of admissions.

We assessed the quality of subgroup effect estimates only if the subgroup analyses were pre-specified and met one or more of the following criteria:

- The subgroup estimate was calculated to explain the presence of substantial heterogeneity in the summary estimate $\left(I^{2} \geq 50 \%\right.$ or chi-squared $\left.P<0.1\right)[20]$.

- The subgroup estimate was calculated from a subset of trials at low risk of bias (as assessed by the original review authors).

- The subgroup estimate showed a significant reduction or increase in hospital admissions, while the summary estimate found no effect.

We considered high and moderate GRADE ratings to represent strong evidence, since the effect estimates are unlikely to change if additional studies are conducted $[18,21]$.

To prioritise the therapies further, we cross-referenced the list of medications supported by high- or moderate-quality evidence with clinical guidelines. We conducted this analysis to ensure that the overall balance of benefit to harm for the therapies had been judged acceptable by key health-care stakeholders. We first cross-referenced the list with National Institute for Health and Care Excellence (NICE) clinical guidelines [22]. NICE is the largest UK-based organisation providing guidance on clinical care across all disciplines. It was selected based on a consensus among our academic-clinician co-authors. NICE recommends therapies based on their clinical appropriateness, safety, cost-effectiveness and feasibility as judged by clinical experts, health economists, administrators, regulators and patients [23]. We then cross-referenced the short list of NICE-recommended treatments with guidelines in Europe and America. We identified the most recent guidelines by searching the National Guideline Clearinghouse maintained by the Agency for Healthcare Research and Quality. If we could not find a relevant guideline, we then searched for national medical associations and 
professional societies providing guidance on the treatment for the patient population of interest. The following guidelines were selected from search results by consensus among our clinical-academic co-authors: European Society of Cardiology [24, 25], European Atherosclerosis Society [26], American Heart Association/ American College of Cardiology [27-29], European Respiratory Society [30], American Thoracic Society [31], European Psychiatric Association [32] and the American Psychiatric Association [33]. To be considered guideline-based, the treatment must have been recommended by NICE and at least one of the American or European guidelines.

\section{Data analysis}

To standardise reporting, we used international classification systems. We described patient populations using the World Health Organization's International Statistical Classification of Diseases and Related Health Problems 10th Revision (WHO ICD-10) [34]. We classified medications using the WHO Anatomical Therapeutic Chemical (WHO ATC) classification system [35]. We used the disease definitions and relevant thresholds provided in the reviews, for example, the cut-off for reduced left ventricular ejection fraction in heart failure (i.e., 45\%). When possible, we converted reported effect estimates into risk ratios (see Additional file 1: Table S2 for conversion methods) [36-39].

For significant effect estimates that underwent quality assessment, we calculated the number needed to treat to avoid one hospitalisation and the number needed to treat to cause one hospitalisation. For each estimate, we used the median control-group event rate from the RCTs in the meta-analysis $[15,33,38-40]$. When data on event rates were unclear or not reported by the review authors, we obtained the original RCTs and extracted the data.

We used Excel for data extraction and management. For the quantitative data analysis, we used STATA 14 [41]. The results are reported in accordance with PRISMA guidance [42].

\section{Results}

We screened 11,442 titles and abstracts and 1563 full text articles (Fig. 1). Of these, 140 systematic reviews met the inclusion criteria. Agreement between reviewers was good for both the title/abstract screen (kappa $=0.85,95 \%$ confidence interval, CI 0.83 to 0.87 ) and full-text screen (kappa $=0.77,95 \%$ CI 0.73 to 0.82 ). Complete references, detailed information and full AMSTAR results for each review are included in Additional file 1: Tables S3, S4 and S5.

Table 1 describes the summary characteristics of the 140 reviews. The median AMSTAR score for review quality was 8/11 (interquartile range 6 to 9). Review quality was most often downgraded because the review authors did not state their potential conflicts of interest (AMSTAR criterion 11).

The reviews included an underlying evidence base of 1968 unique RCTs (925,364 patients), of which 690 RCTs reported hospital admission outcomes for 577,604 patients. The number of RCTs underpinning the treatment comparisons ranged from 1 to 184 (median 3), with patient sample sizes ranging from 18 to 88,367 (median 1116). The reviews contained data on 100 unique medications tested in 47 patient populations (Additional file 1: Table S6). Altogether, 125 reviews (89\%) examined therapies for patients with chronic diseases. Much of the evidence was for patients with circulatory diseases (53 reviews, 38\%) or respiratory diseases (56 reviews, 40\%). The most common conditions were heart failure (35 reviews, $25 \%$ ), chronic obstructive pulmonary disease (COPD; 27 reviews, 19\%), acute exacerbations of asthma (20 reviews, 14\%) and chronic asthma (14 reviews, 10\%). Hospital admissions were identified as a primary outcome in 61 of the reviews (44\%). Seventy-eight reviews (56\%) reported significantly fewer hospital admissions in intervention arms compared with control arms, while a small minority (8 reviews, 6\%) reported significant increases because of the intervention.

\section{Prioritised list of evidence- and guideline-based medications that significantly reduce emergency hospital admissions}

From the 140 included reviews, we extracted 517 treatment comparisons that reported hospital admission outcomes (Fig. 2). All treatment comparisons are available in the online database supplement (Additional file 2: Database 1). Of the 517 comparisons, 159 had pooled effect estimates showing a statistically significant effect on hospital admissions. Using GRADE criteria, we identified high and moderate evidence for 28 medications that significantly reduced hospital admissions in 15 patient populations. Evidence summaries for all graded estimates showing a significant reduction in admissions are given in Additional file 1: Table S7.

Of the 28 medications with high- or moderate-quality evidence, 11 were supported by clinical guidelines from the United States, United Kingdom or Europe. Table 2 shows the evidence summaries for these therapies. These 11 medications were tested in 12 comparisons; aldosterone antagonists were tested in two different heart failure groups. Nine treatments were tested against a placebo and three against an active comparator.

There were seven treatments that reduced admissions from out-patient, day-procedure or community settings in patients with heart failure, stable coronary artery disease or stable COPD, while two treatments reduced admissions among patients with acute asthma in the 


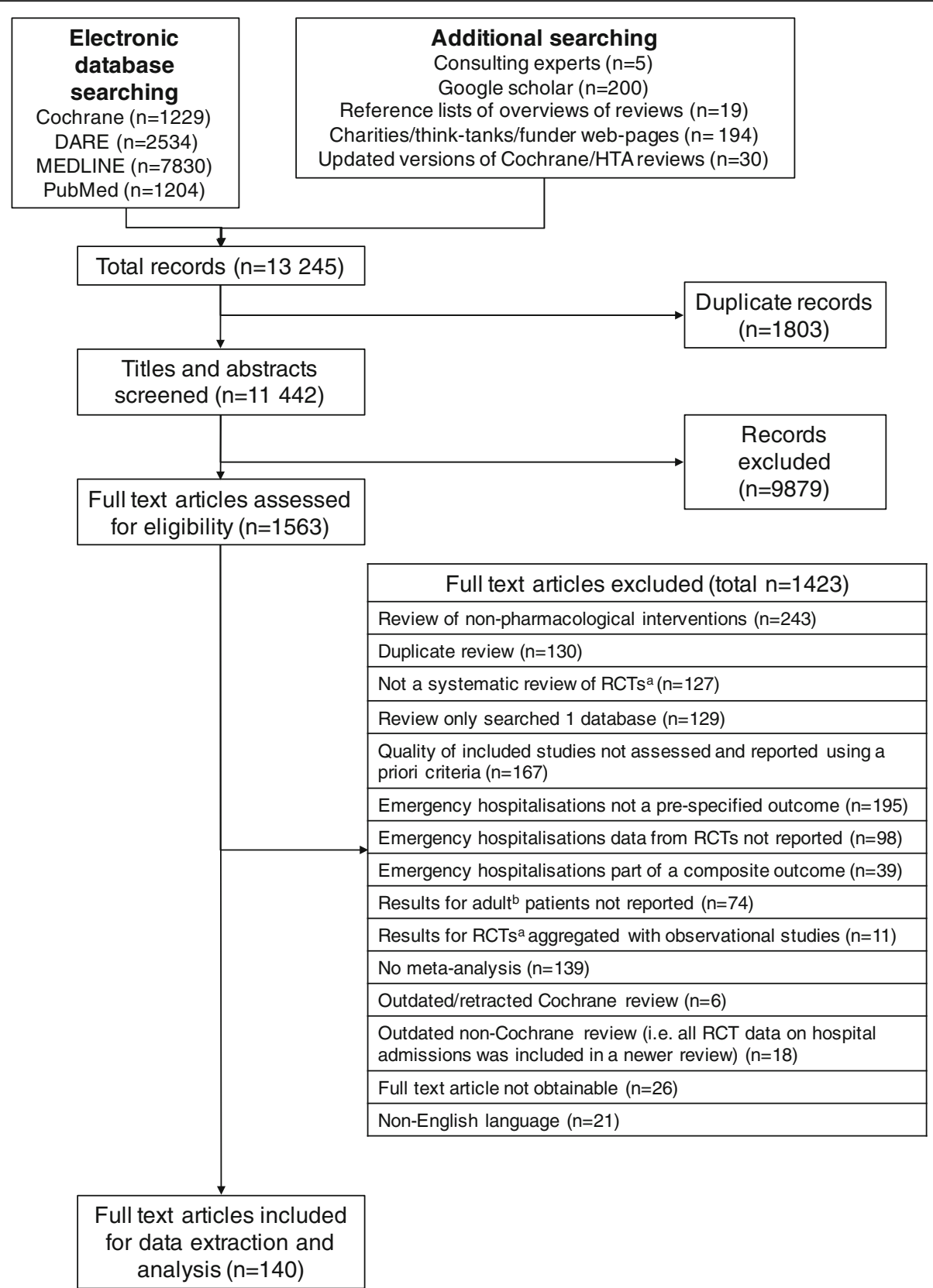

Fig. 1 PRISMA flow diagram of study selection. ${ }^{a}$ Randomised controlled trial. ${ }^{b}$ Individual RCTs were defined as adult if they had inclusion criteria of 16 years of age or older for participants. We considered results from a meta-analysis as adult if the included participants' mean age was 18 years or more across all included trials. RCT randomised controlled trial

emergency department, and two treatments reduced readmissions after index hospitalisation among patients with schizophrenia.

Information on the drugs, dosing, length of follow-up, ages and event rates from the RCTs that contributed data to the high- and moderate-quality effect estimates is listed in Additional file 1: Table S8. Information on the GRADE quality assessments for each estimate is presented in Additional file 1: Table S9.

\section{Medications that increase admissions}

While reviewing the evidence for medications that reduced admissions, we also identified high- and moderate-quality evidence for three therapies that significantly increased hospital admissions: cyclooxygenase-2 (COX-2) inhibitors in patients for whom non-steroidal anti-inflammatory drugs (NSAIDs) were indicated, intermittent antipsychotic drug therapy in patients with schizophrenia and fluticasone in patients with COPD (Table 3). Evidence summaries for 
Table 1 Summary characteristics of included systematic reviews and the randomised controlled trial data captured by the reviews

\begin{tabular}{|c|c|}
\hline Characteristic & $\begin{array}{l}\text { Reviews } \\
n(\%)\end{array}$ \\
\hline \multicolumn{2}{|l|}{ Review level information $(n=140)$} \\
\hline Cochrane reviews & $49(35)$ \\
\hline Number of unique medications investigated ${ }^{a}$ & 100 \\
\hline Number of unique patient populations investigated ${ }^{\mathrm{b}}$ & 47 \\
\hline Reviews focusing on medications for patients with chronic diseases & $125(89)$ \\
\hline \multicolumn{2}{|l|}{ Patient population ${ }^{c}$} \\
\hline Diseases of the respiratory system & $56(40)$ \\
\hline Diseases of the circulatory system & $53(38)$ \\
\hline Factors influencing health status and contact with health services ${ }^{d}$ & $8(6)$ \\
\hline Diseases of the digestive system & $8(6)$ \\
\hline Mental and behavioural disorders & $7(5)$ \\
\hline Diseases of the genitourinary system & $5(4)$ \\
\hline Pregnancy, childbirth and puerperium & $5(4)$ \\
\hline Endocrine, nutritional and metabolic diseases & $5(4)$ \\
\hline Mixed patient populations & $3(2)$ \\
\hline Multi-morbidity & $2(1)$ \\
\hline Other ${ }^{\mathrm{e}}$ & $4(3)$ \\
\hline Hospitalisation was a primary outcome & $61(44)$ \\
\hline Review reported pooled effect estimates showing significant reductions in hospital admissions & $78(56)$ \\
\hline AMSTAR score for review quality, median (IQR) & $8(6$ to 9$)$ \\
\hline \multicolumn{2}{|l|}{ Review year of publication } \\
\hline 2010-2016 & $96(69)$ \\
\hline 2000-2009 & $42(30)$ \\
\hline 1991-1999 & $2(1)$ \\
\hline \multicolumn{2}{|l|}{ Randomised controlled trial (RCT) information } \\
\hline Number of unique RCTs & 1968 \\
\hline Number of unique patients & 925,364 \\
\hline Number of unique RCTs reporting admissions data & 690 \\
\hline Number of unique patients with admissions data & 577,604 \\
\hline Number of patients per RCT reporting hospital admission outcomes, median (IQR) & 190 (62 to 603$)$ \\
\hline Number of treatment comparisons reporting hospital admission outcomes & 517 \\
\hline
\end{tabular}

AMSTAR Assessing the Methodological Quality of Systematic Reviews, IQR interquartile range, $R C T$ randomised controlled trial

annique at the level of pharmacological subgroup in the World Health Organization's Anatomical Therapeutic Chemical classification system

bunique at the three-character coding level using the 10th revision of the World Health Organization's International Statistical Classification of Diseases and

Related Health Problems (ICD-10)

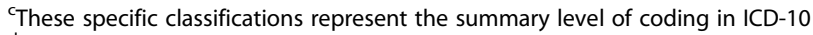

${ }^{\mathrm{d}}$ For example, patients receiving day surgery

e Infection and parasitic disease ( $n=1$ review), diseases of the musculoskeletal system and connective tissue ( $n=1$ review), and diseases of the nervous system

( $n=2$ reviews)

graded estimates showing a significant increase in admissions are given in Additional file 1: Table S10. Information on the drugs, dosing, length of follow-up, ages and event rates from the RCTs that contributed data to the high- and moderate-quality effect estimates is listed in Additional file 1: Table S8. Information on the GRADE quality assessments for each estimate is presented in Additional file 1: Table S9.

\section{Discussion}

\section{Summary of findings}

We examined 140 reviews of 100 medications, and identified high- to moderate-quality evidence for 28 therapies that significantly reduced admissions in 15 different populations. Eleven of these therapies were supported by major clinical guidelines from the United States, the United Kingdom or Europe. We also identified high- and 


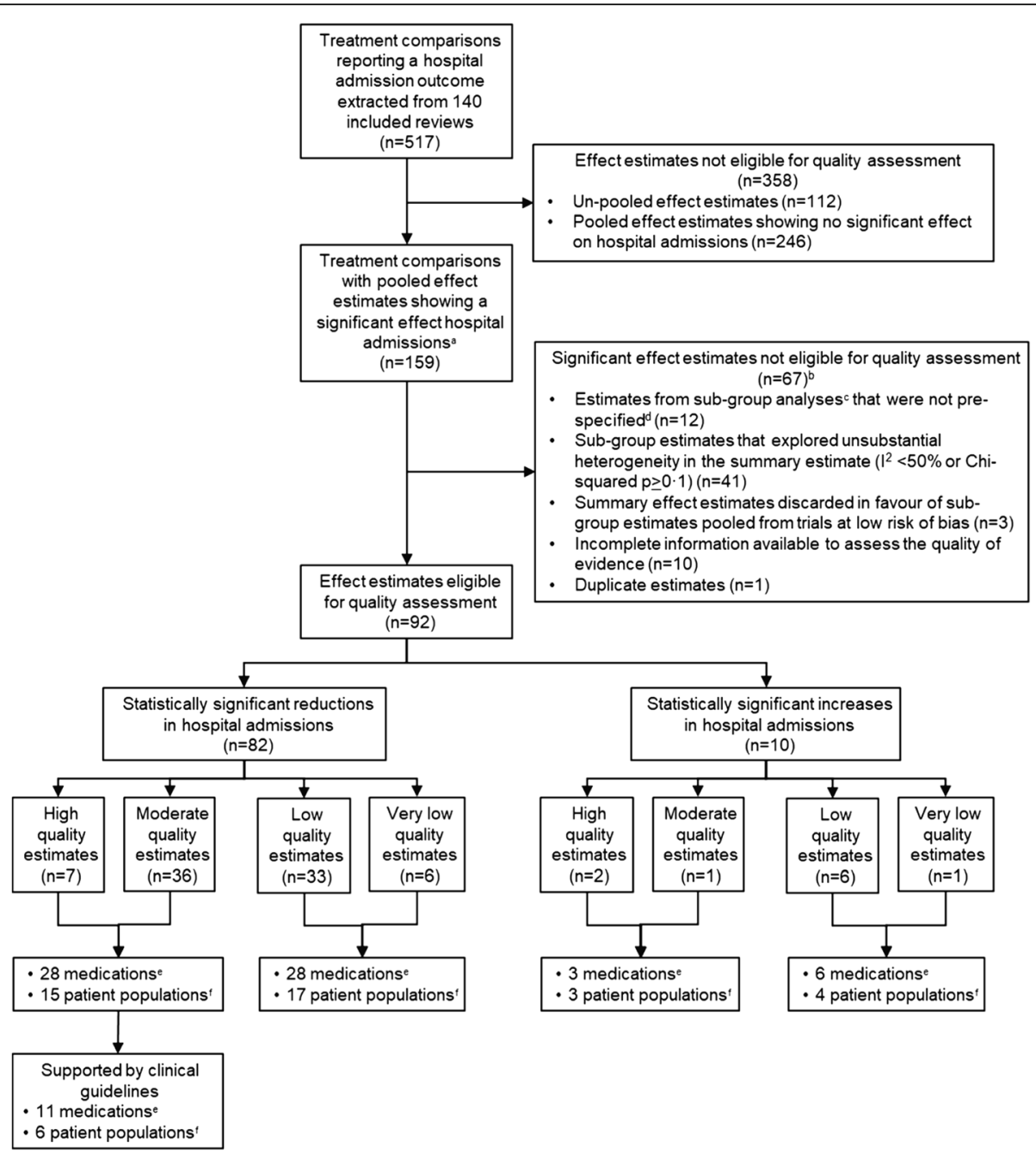

Fig. 2 Flow diagram of the process to identify effective medications supported by high- or moderate-quality evidence. ${ }^{a}$ Statistically significant at the $p<0.05$ level. ${ }^{b}$ Estimates were for subgroup estimates that did not meet our criteria for quality assessment. ${ }^{C}$ Subgroup or sensitivity analysis as defined by authors. ${ }^{d}$ Pre-specified in the methods section of the review article. ${ }^{e}$ Unique at the level of pharmacological subgroup in the World Health Organization's Anatomical Therapeutic Chemical classification system. 'Unique at the three-character coding level using the World Health Organization's 10th revision of the International Statistical Classification of Diseases and Related Health Problems

moderate-quality evidence for three medications that increased admissions.

\section{In the context of the literature}

Previous reviews of interventions to reduce hospital admissions have focused on non-pharmacological initiatives [10, 43-45]. Our study, therefore, fills an important gap as the first systematic investigation of medications that affect hospital admissions. We mapped a large evidence base and prioritised therapies based on the quality of the evidence and support of clinical guidelines.

Our results complement a growing body of evidence about drug-related hospital admissions. Several systematic reviews of observational studies have shown that approximately $3 \%$ of all emergency hospitalisations are related to suspected adverse drug reactions and drug- drug interactions [46-51]. Drugs often associated with hospital admissions include antiplatelet drugs, diuretics, renin-angiotensin system blockers, NSAIDs and anticoagulants. However, the reviews have not considered the number of admissions these drugs help to avoid and therefore, have not provided evidence about their net effects on admissions. Our study complements this literature, as it shows a strong body of evidence supporting a beneficial reduction in admissions for renin-angiotensin system blockers [angiotensin-converting-enzyme (ACE) inhibitors and angiotensin II receptor blockers] and aldosterone receptor antagonists. We have also identified strong evidence for a harmful increase in cause-specific admissions due to heart failure from the use of COX2 inhibitors and pneumonia from the use of inhaled corticosteroids in COPD patients. Many of the other drugs 


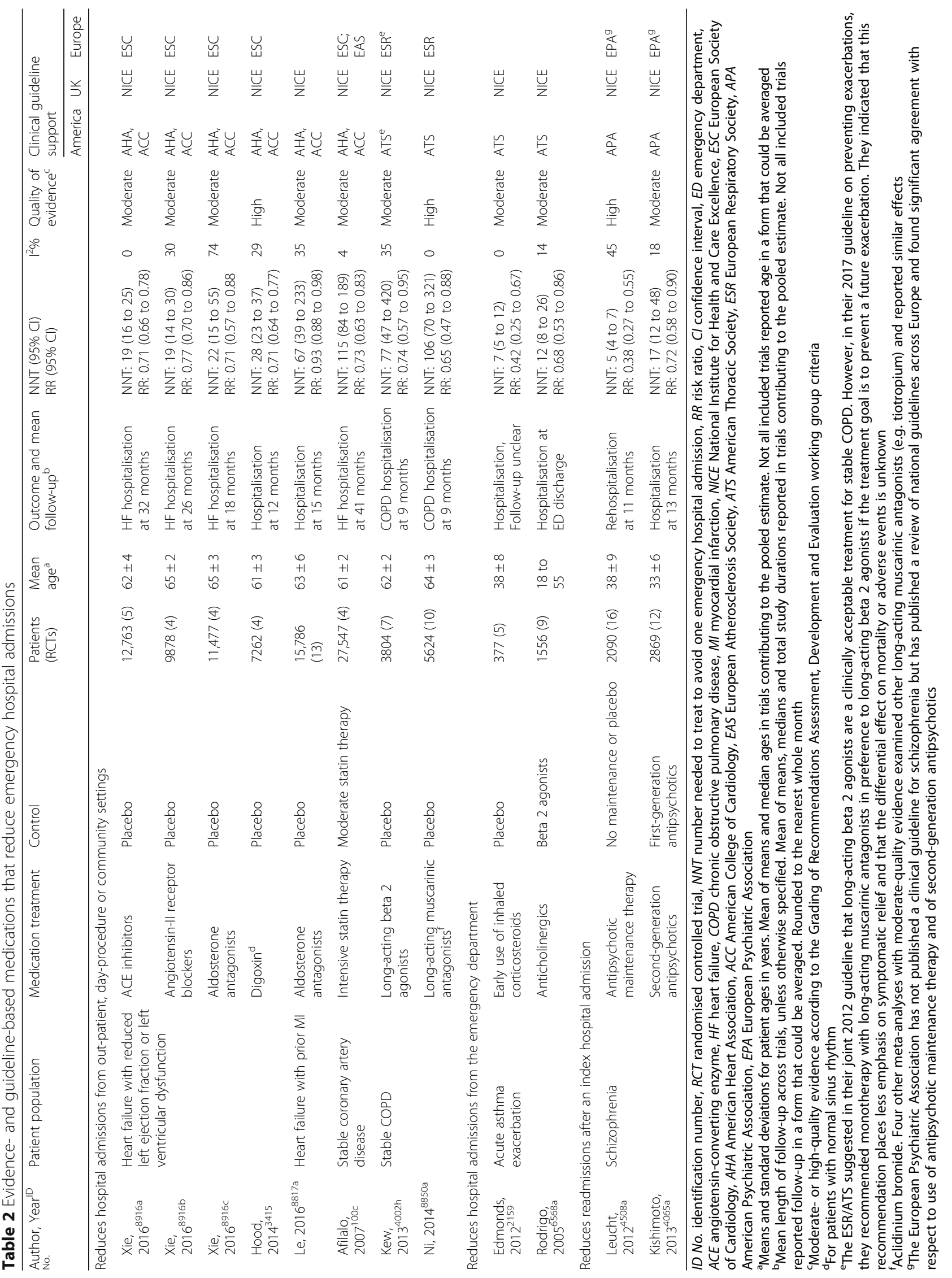


commonly associated with drug-related admissions did not appear in our study. Several reviews of RCTs focusing on antiplatelet drugs and anticoagulants were excluded, because they reported admissions as part of composite outcomes. The net effect of antiplatelet drugs and anticoagulants on hospital admissions is, therefore, not clear from the published systematic review literature.

\section{Implications for practice}

Policymakers and commissioners may use these results to prioritise quality measurement and improvement efforts. We have systematically identified a list of 11 evidenceand guideline-based treatments for five major chronic diseases: heart failure, stable coronary artery disease, COPD, asthma and schizophrenia. These diseases cause millions of hospital admissions each year globally [52-56] and account for about $5 \%$ of all emergency admissions in high-income countries [57-59]. Yet, there is evidence of significant variation in the prescribing of some these 11 therapies in the United States and Europe, including under-dosing and under-prescribing [60-62]. Therefore, improving utilisation of these medications could translate to substantial reductions in hospital admissions. Potential improvement targets include minimising gaps in prescribing, correcting over- and under-dosing, and improving patient adherence, although the specific target of any improvement initiatives should be driven by locally identified shortfalls in care.

The results of this study may be fed into existing mechanisms for tracking and improving clinical practices in health systems. Prescribing data for some of the 11 evidence- and guideline-based medications are currently monitored in several health systems, for example, use of ACE inhibitors, angiotensin II receptor blockers and beta blockers is currently measured as part of the UK Quality and Outcomes Framework, a pay-for-performance incentive structure that has demonstrably reduced prescribing gaps for these medications and improved prescribing efficiency for other medications [63-65]. All of the top 11 medications we identified could be considered for inclusion in these types of quality assurance and incentive structures. This pathway to optimising medication utilisation may be a feasible strategy to help reduce emergency hospital admissions.

For some of the therapies in this review, bridging treatment gaps and improving prescribing may result in immediate benefits and may rely only on a small number of stakeholders. For example, we found evidence that treating patients with acute exacerbations of asthma in the emergency department with inhaled corticosteroids or anticholinergics helped to avoid hospital admissions. Optimal utilisation of these medications could be achieved through direct efforts by emergency department physicians and hospital pharmacists.
However, many of the therapies in this review form part of ongoing chronic disease management, and beneficial effects occur after months of use. Optimal utilisation of these medications would require coordination of multiple stakeholders, including physicians in different specialties, home care or case management nurses, community pharmacists and patients.

We can estimate potential reductions in hospital admissions by combining the results of our study with data on existing treatment gaps and disease prevalence. For example, in studies of prescribing for heart failure in the United States and Europe, 13\% of patients with reduced left ventricular ejection fractions who are eligible for treatment do not receive the first-line therapy $[60,66]$. It has been estimated that $1.5 \%$ of people in developed countries have heart failure, of whom $40 \%$ have reduced ejection fractions [52, 67-69]. Therefore, about 400,000 Europeans and 250,000 Americans with heart failure and reduced ejection fractions are eligible for first-line therapy but are not receiving it [70]. Based on the numbers needed to treat and baseline hospitalisation event rates that we have reported for ACE inhibitors and angiotensin II receptor blockers, closing these treatment gaps could help to avoid approximately 28,000 (95\% CI 24,000 to 37,000) hospital admissions in Europe and 18,000 (95\% CI 15,000 to 24,000 ) admissions in the United States per year.

Our results also reinforce the dangers of prescribing COX2 inhibitors, particularly for patients at risk of cardiovascular disease, inhaled corticosteroids in patients with moderate to severe stable COPD, and intermittent antipsychotic drug therapy for patients with schizophrenia. It is, therefore, reassuring that the harms associated with the use of these drugs and steps to ensure that they are used appropriately, if at all, have been reported widely in clinical and government prescribing guidelines [71-73].

In addition to high- and moderate-quality evidence, this study identified 28 medications with low- and very low-quality evidence for reducing admissions. According to the GRADE working group, these estimates for reducing admissions are likely to change if additional research were conducted [18]. Therefore, given the uncertainty around the estimates of effects for these 28 medications, we would not recommend prioritising these for reducing emergency admissions. However, we recognise that the level of evidence required to act may vary depending on the circumstances, the stakeholders involved and the available evidence (which may change over time). If limited evidence is available and there is a pressing need to act, lower-quality evidence may be sufficient to justify cautious implementation of an intervention. Our prioritisation of medications with high- and moderate-quality evidence does not prevent stakeholders from using the low- and very low-quality evidence if 


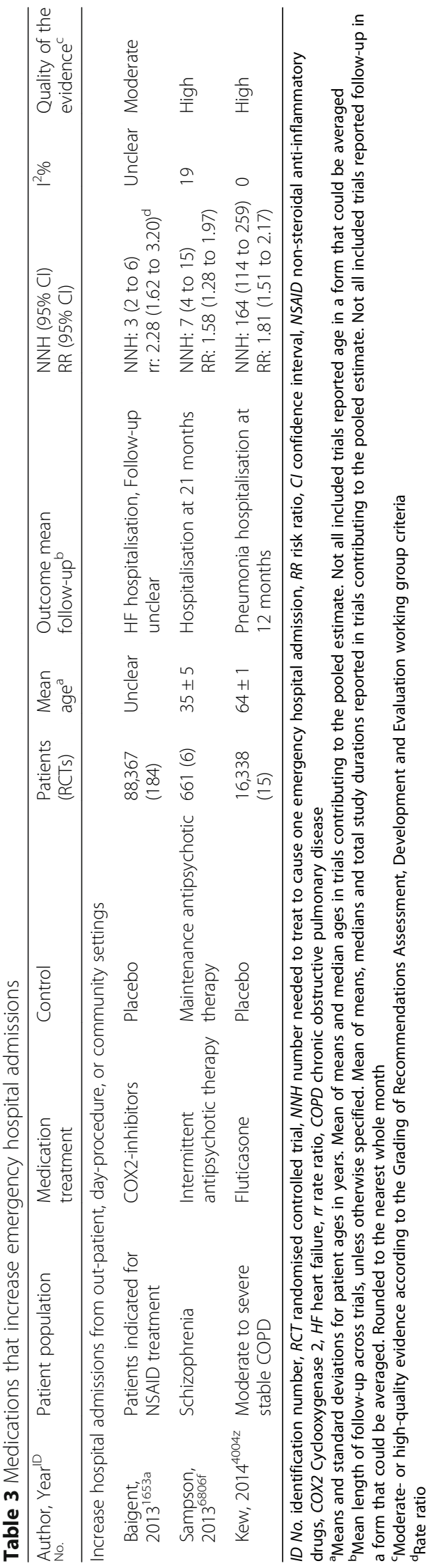


justified in the context of their health-care settings; however, we recommend a robust evaluation to ensure resources are appropriately allocated to those interventions most likely to impact on practice.

\section{Implications for research}

Only $1 \%$ of the reviews examined the effect of medications in patients with multi-morbidity. Given the challenges of effective clinical management and high hospitalisation risk for patients with multiple diseases [47, 74], we need to identify which medication combinations most help multi-morbid patients to avoid hospitalisation.

Low- and very low-quality evidence indicates the need for high-quality research to increase confidence in the reliability of effect estimates. Some of the medications in this overview were supported by low- and very low-quality evidence, suggesting a need for additional high-quality research. Hospitalisations, however, are only one important patient and health system outcome. A larger set of core outcomes that reflect patient and health system priorities should be considered when establishing research priorities, including assessment of mortality, adverse events, quality of life and cost.

Similarly, there were 17 drugs with high- and moderatequality evidence that were not supported by clinical guidelines. We did not record whether the medications had been evaluated. In formulating guidelines, the effect of an intervention on reducing emergency admissions would form only one of many criteria considered by multi-disciplinary panels of stakeholders. We would not recommend that drugs be included in guidelines or considered for inclusion solely because they reduce hospital admissions.

Researchers should consider reporting rates of hospital admissions, as opposed to ratio measures; 476 of the 517 (92\%) effect estimates we reviewed were reported as odds or risk ratios. These are crude measures of hospitalisation, as they assess admission as a binary outcome: present or absent. These effect measures equate a patient who has had one admission during follow-up with a patient who has had five admissions. In patients with chronic diseases, such as heart failure or COPD, for which hospital admissions are common, rate-based measures may have greater utility in evaluating the effectiveness of interventions.

\section{Strengths and limitations of the study}

This study has three key strengths. First, it was comprehensive. We identified, analysed and synthesised information on nearly one million patients to identify the highest quality evidence for medications that affect emergency hospital admissions. Secondly, we minimised the impact of duplicate RCT evidence between reviews by excluding outdated reviews; every review we included has a unique set of hospital admission data. Thirdly, we classified all patient populations using ICD-10 and therapies using WHO
ATC. This helped to homogenise and simplify the data, which was heterogeneously reported in the systematic reviews. When possible, we also converted quantitative data to comparable measures and units (i.e. risk ratios for estimates and months for follow-up duration). This will enable users of our review to navigate and interpret this large body of evidence.

This study has some limitations. First, although we extracted and reported all effect estimates, we have conducted only quality assessments on significant estimates. While it may be useful for decision makers to know the quality of evidence for all tested interventions, our aim was to support decision-making by identifying and prioritising therapies for which an effect has been demonstrated. All the estimates are listed in the online database (Additional file 2). Secondly, we planned to examine secondary outcomes, such as mortality and cost; however, feasibility concerns emerged during the conduct of the review. Therefore, we analysed only our primary outcome, hospital admissions. To provide information about other outcomes, we have extracted and presented conclusions from the abstract of each review. Furthermore, medications that were supported by high- or moderate-quality evidence were cross-referenced with clinical guidelines to identify those for which the overall balance of benefit to harm was judged to be acceptable by key health-care stakeholders. Thirdly, we excluded reviews that reported hospital admissions only as part of a composite end point. We may, therefore, have excluded potentially valuable therapies. However, by excluding composite outcomes, we can be confident that the effective therapies we identified have a significant effect on hospital admissions. Fourthly, we analysed clinical guidelines from at least one national organisation in the UK, Europe or America and identified support for 11 of the medications in this overview. However, it is possible that there are other relevant clinical guidelines that we did not analyse that support additional medications from this study. Readers of the overview may combine the findings with relevant clinical guidelines in their field to identify additional medications that may be considered for quality measurement and improvement to reduce hospital admissions. Fifthly, our GRADE ratings of indirectness were assessed by generalist clinicians and it is possible that clinical specialists (e.g. cardiologists) may have different opinions regarding the comparability of certain subgroups of patients and interventions. Finally, we planned to include reviews in all languages; however, feasibility concerns emerged during the conduct of the review and as a result we included only reviews published in English. Therefore, we may have missed effective therapies examined in non-English reviews.

\section{Conclusions}

We identified 11 medications supported by strong evidence and clinical guidelines that could be considered in 
quality monitoring and improvement strategies to help reduce emergency hospital admission rates. The findings are relevant to health systems with a large burden of chronic disease and those managing increasing pressures on acute health-care services.

\section{Additional files}

Additional file 1: Table S1. Search strategies and results of searches. Table S2. Formulae and calculations used in analyses. Table S3. Complete references. Table S4. Information about included reviews. Table S5. Full results for AMSTAR review quality assessment. Table S6. Distribution of evidence by patient population. Table S7. GRADE estimates showing reductions in admissions. Table S8. Trial information underpinning GRADE estimates. Table S9. Details of GRADE ratings. Table S10. GRADE estimates showing an increase in admissions. (PDF $47591 \mathrm{~kb})$

Additional file 2: Database 1. (XLSX $130 \mathrm{~kb})$

\section{Acknowledgments}

We would like to thank Dr Karen Kearley, Clinical Director for Research and Development on the Oxfordshire clinical commissioning group, and Dr Raj Bajwa, clinical general practice chair of the Chiltern clinical commissioning group, who provided input on the methods and framing of this manuscript so that it may better inform health-care decision-making. The opinions expressed in this study are those of the authors and not necessarily those of the NIHR, the Department of Health or the NHS.

\section{Funding}

This was an unfunded study. NB was funded by a Clarendon Scholarship, a Goodger and Schorstein Scholarship, and the National Institute for Health Research School for Primary Care Research.

\section{Availability of data and materials}

All data generated or analysed during this study are included in this published article (and Additional files 1 and 2).

\section{Authors' contributions}

$\mathrm{NB}, \mathrm{CH}, \mathrm{IO}, \mathrm{NR}, \mathrm{DN}$ and $\mathrm{KM}$ contributed to the design of the study. NB, CH, IO, NR, DN, KM, DC, BF, AT, JL, RF, BS, JO, OH, BN and SS contributed to the acquisition and analysis of data. The data was interpreted by NB, CH, IO, BF, $D C, D N$ and $K M$. The manuscript was drafted by NB, CH, DC and KM, and was critically revised for important content by all authors. All authors approved the final version of the manuscript to be published. All authors agreed to be accountable for all aspects of the work.

\section{Ethics approval and consent to participate}

This study did not require ethical approval.

\section{Consent for publication}

Not applicable.

\section{Competing interests}

All authors have completed the uniform disclosure form of the International Committee of Medical Journal Editors at www.icmje.org/coi_disclosure.pdf and declare the following. They have not had any support from any organisation for the submitted work. They have not had any financial relationship with any organisations that might have an interest in the submitted work in the previous 3 years. There have been no other relationships or activities that could appear to have influenced the submitted work. One of our co-authors $(\mathrm{CH})$ was an author of a study included in this review (Neuraminidase inhibitors for preventing and treating influenza in healthy adults and children). This did not influence the current submitted work.

\section{Publisher's Note}

Springer Nature remains neutral with regard to jurisdictional claims in published maps and institutional affiliations.

\section{Author details}

"Nuffield Department of Primary Care Health Sciences, University of Oxford, Radcliffe Observatory Quarter, Woodstock Road, Oxford OX2 6GG, United Kingdom. ${ }^{2}$ Centre for Evidence-Based Medicine, University of Oxford, Oxford, United Kingdom. ${ }^{3}$ Faculty of Medicine, University of British Columbia, Vancouver, Canada. ${ }^{4}$ Faculty of Public Health and Policy, London School of Hygiene and Tropical Medicine, London, United Kingdom. ${ }^{5}$ The Health Foundation, London, United Kingdom. ${ }^{6}$ Department of Critical Care Medicine, University of Calgary, Calgary, Canada. ${ }^{7}$ Snyder Institute for Chronic Diseases, University of Calgary, Calgary, Canada. ${ }^{8}$ Bodelian Libraries, University of Oxford, Oxford, UK.

Received: 8 February 2018 Accepted: 19 June 2018

Published online: 26 July 2018

\section{References}

1. Kohn LT, Donaldson MS, Institute of Medicine, CJM. To Err Is Human: Building a Safer Health System. Washington, DC: National Academy Press; 2000.

2. Burke JP. Infection control - a problem for patient safety. N Engl J Med. 2003;348(7):651-6. https://doi.org/10.1056/NEJMhpr020557.

3. Klevens RM, Edwards JR, Richards CL Jr, et al. Estimating health careassociated infections and deaths in U.S. hospitals, 2002. Public Heal Rep. 2007;122(2):160-6. http://www.ncbi.n/m.nih.gov/pubmed/17357358

4. Kaier K, Mutters NT, Frank U. Bed occupancy rates and hospital-acquired infections-should beds be kept empty? Clin Microbiol Infect. 2012;18(10): 941-5. https://doi.org/10.1111/j.1469-0691.2012.03956.x.

5. Forero R, Hillman KM, McCarthy S, Fatovich DM, Joseph AP, Richardson DB. Access block and ED overcrowding: Short Report. Emerg Med Australas. 2010;22(2):119-35. https://doi.org/10.1111/j.1742-6723.2010.01270.x.

6. National Audit Office Department of Health. Emergency Admissions to Hospital: Managing the Demand. 2013. http://www.nao.org.uk/wp-content/ uploads/2013/10/10288-001-Executive-Summary.pdf.

7. Department of Health. Department of Health Annual Report and Accounts. 2016;16:2015-16. https://assets.publishing.service.gov.uk/government/ uploads/system/uploads/attachment_data/file/539602/DH_Annual_Report_ Web.pdf.

8. British Broadcasting Corporation. Hospital admissions in England reach new high. 2016. http://www.bbc.co.uk/news/health-37924167. Accessed 1 Aug 2017.

9. National Health Service England. A\&E Attendances and Emergency Admissions 2016-17. England Time Series. 2017. https://www.england.nhs. uk/statistics/statistical-work-areas/ae-waiting-times-and-activity/statisticalwork-areasae-waiting-times-and-activityae-attendances-and-emergencyadmissions-2016-17/. Accessed 1 Aug 2017.

10. Purdy S, Alyson H, Rebecca T, Mala M, Dyfed H, Peter B, Glyn Ee SP. Interventions to Reduce Unplanned Hospital Admission: A Series of Systematic Reviews. Bristol: University of Bristol; 2012.

11. Leppin AL, Gionfriddo MR, Kessler M, et al. Preventing 30-Day Hospital Readmissions: A Systematic Review and Meta-analysis of Randomized Trials. JAMA Intern Med. 2014; https://doi.org/10.1001/jamainternmed.2014.1608.

12. Xie W, Zheng F, Song X, Zhong B, Yan L. Renin-angiotensin-aldosterone system blockers for heart failure with reduced ejection fraction or left ventricular dysfunction: Network meta-analysis. Int J Cardiol. 2016;205:65-71. https://doi.org/10.1016/j.ijcard.2015.12.010.

13. Becker L, Oxman A. Overviews of reviews. Cochrane Handbook for Systematic Reviews of Interventions Version 5.1.0. 2011. http://training. cochrane.org/handbook.

14. Bobrovitz N, Onakpoya I, Roberts N, Mahtani K, Heneghan C. An overview of systematic reviews of interventions to reduce unplanned hospital admissions among adults. PROSPERO 2014 CRD42014014779 Available from: http://www.crd.york.ac.uk/PROSPERO/display_record.php?ID= CRD42014014779

15. Bobrovitz N, Onakpoya I, Roberts N, Heneghan C, Mahtani KR. Protocol for an overview of systematic reviews of interventions to reduce unscheduled hospital admissions among adults. BMJ Open. 2015;5(8):1-7. https://doi.org/ 10.1136/bmjopen-2015-008269.

16. National Health Service data model and dictionary service. Data dictionary. 2017. http://www.datadictionary.nhs.uk/data_dictionary/attributes/a/add/ admission_method_de.asp. Accessed 1 June 2014. 
17. Shea BJ, Hamel C, Wells GA, et al. AMSTAR is a reliable and valid measurement tool to assess the methodological quality of systematic reviews. J Clin Epidemiol. 2009;62(10):1013-20. https://doi.org/10.1016/j.jclinepi.2008.10.009.

18. Schünemann H, Brożek J, Guyatt G, Oxman A. GRADE Handbook: Handbook for grading the quality of evidence and the strength of recommendations using the GRADE approach. 2013. http://gdt.guidelinedevelopment.org/app/ handbook/handbook.html\#h.9rdbelsnu4iy. Accessed 1 June 2014.

19. Office for National Statistics. United Kingdom population mid-year estimate. 2017. https://www.ons.gov.uk/peoplepopulationandcommunity/ populationandmigration/populationestimates/timeseries/ukpop/pop.

20. Higgins JPT, Green S (editors). Cochrane Handbook for Systematic Reviews of Interventions Version 5.1.0 [updated March 2011]. The Cochrane Collaboration, 2011. Available from http://handbook.cochrane.org.

21. Guyatt GH, Oxman AD, Schünemann HJ, Tugwell P, Knottnerus A. GRADE guidelines: a new series of articles in the Journal of Clinical Epidemiology. J Clin Epidemiol. 2011;64(4):380-2. https://doi.org/10.1016/j.jclinepi.2010.09.011.

22. National Institute for Health and Care Excellence. NICE Guidance. 2017. https://www.nice.org.uk/guidance. Accessed 1 Aug 2017.

23. National Institute for Health and Care Excellence. Developing NICE Guidelines: The Manual. 2014. https://www.nice.org.uk/Media/Default/About/what-we-do/ our-programmes/developing-NICE-guidelines-the-manual.pdf.

24. Ponikowski P, Voors AA, Anker SD, et al. 2016 European Society of Cardiology Guidelines for the diagnosis and treatment of acute and chronic heart failure. Eur Heart J. 2016;37(27):2129-2200m. https://doi.org/10.1093/ eurheartj/ehw128.

25. Montalescot G, Sechtem U, Achenbach S, et al. 2013 European Society of Cardiology guidelines on the management of stable coronary artery disease. Eur Heart J. 2013;34(38):2949-3003. https://doi.org/10.1093/ eurheartj/eht296.

26. Reiner Ž, Catapano AL, De Backer G, et al. European Society of Cardiology/ European Atherosclerosis Society Guidelines for the management of dyslipidaemias. Eur Heart J. 2011;32(14):1769-818. https://doi.org/10.1093/ eurheartj/ehr158.

27. Yancy CW, Jessup M, Bozkurt B, et al. 2013 ACCF/AHA guideline for the management of heart failure: Executive summary: A report of the American college of cardiology foundation/american heart association task force on practice guidelines. J Am Coll Cardiol. 2013;62(16):1495-539. https://doi.org/ 10.1016/j.jacc.2013.05.020.

28. Fihn SD, Blankenship JC, Alexander KP, et al. 2014 ACC/AHAVAATS/PCNA/SCAI/ STS Focused Update of the Guideline for the Diagnosis and Management of Patients With Stable Ischemic Heart Disease: A Report of the American College of Cardiology /American Heart Association Task Force on Practice Cardiovascul, vol. 130; 2014. https://doi.org/10.1161/CIR.00000000000.

29. Yancy CW, Jessup M, Bozkurt B, Butler J, Casey DE Jr, Colvin MM, Drazner MH, Filippatos GS, Fonarow GC, Givertz MM, Hollenberg SM, Lindenfeld J, Masoudi FA, PE MB, Peterson PN, Stevenson LWWC. 2017 ACC/AHA/HFSA Focused Update of the 2013 ACCF/AHA Guideline for the Management of Heart Failure: A Report of the American College of Cardiology/American Heart Association Task Force on Clinical Practice Guidelines and the Heart Failure Society; 2017. https://doi.org/10.1161/CIR.0000000000000509.

30. Wedzicha JA, Calverley PMA, Albert RK, et al. Prevention of COPD exacerbations: a European Respiratory Society/American Thoracic Society guideline. Eur Respir J. 2017;50(3):1602265. https://doi.org/10.1183/13993003. 02265-2016

31. Schatz M, Kazzi AAN, Brenner B, et al. Managing Asthma Exacerbations in the Emergency Department: Summary of the National Asthma Education and Prevention Program Expert Panel Report 3 Guidelines for the Management of Asthma Exacerbations. Proc Am Thorac Soc. 2009;6(4):3536. https://doi.org/10.1513/pats.P09ST1

32. Gaebel W, Weinmann S, Sartorius N, Rutz W, Mclntyre JS. Schizophrenia practice guidelines: international survey and comparison. Br J Psychiatry J Ment Sci. 2005;187:248-55.

33. Dixon LB, Perkins DO, Mcintyre JS. Treatment of Patients With Schizophrenia Second Edition. Psychiatr Serv. 2004;161:i-iv+1-56. https://doi.org/10.1037/ 0003-066X.57.12.1052.

34. World Health Organisation. International Statistical Classification of Disease and Related Health Problems Version 10. 2016. http://apps.who.int/ classifications/icd10/browse/2016/en. Accessed 1 June 2015.

35. World Health Organisation Collaborating Centre for Drug Statistics Methodology. Anatomical Therapeutic Chemical classification index. Oslo; 2016. https://www.whocc.no/atc_ddd_index/. Accessed 1 June 2015
36. The Cochrane Collaboration. Chapter 11.5.5 Statistical considerations in "Summary of findings" tables. Cochrane Handbook for Systematic Reviews of Interventions. 2011. http://training.cochrane.org/handbook.

37. Zhang J, Yu KF. What's the relative risk? A method of correcting the odds ratio in cohort studies of common outcomes. JAMA. 1998;280(19):1690-1. https://doi.org/10.1001/jama.280.19.1690.

38. The Centre for Evidence-Based Medicine. Number Needed to Treat (NNT). 2012. http://www.cebm.net/number-needed-to-treat-nnt/. Accessed 1 June 2014

39. Newcombe RG, Bender R. Implementing GRADE: calculating the risk difference from the baseline risk and the relative risk. Evid Based Med. 2014; 19(1):6-8. https://doi.org/10.1136/eb-2013-101340.

40. Newcombe RG. MOVER-R confidence intervals for ratios and products of two independently estimated quantities. Stat Methods Med Res. 2013 https://doi.org/10.1177/0962280213502144.

41. StataCorp. Stata Statistical Software: Release 14. 2015

42. Moher D, Liberati A, Tetzlaff J, Altman DG, Grp P. Preferred Reporting Items for Systematic Reviews and Meta-Analyses: The PRISMA Statement (Reprinted from Annals of Internal Medicine). Phys Ther. 2009;89(9):873-80. https://doi.org/10.1371/journal.pmed.1000097.

43. Thomas R, Huntley A, Mann M, et al. Specialist clinics for reducing emergency admissions in patients with heart failure: a systematic review and meta-analysis of randomised controlled trials. Heart. 2013;99(4):233-9. https://doi.org/10.1136/heartjnl-2012-302313.

44. Coon J, Martin A, Abdul-Rahman A, et al. Interventions to reduce acute paediatric hospital admissions: A systematic review. Arch Dis Child. 2012; 97(Suppl 1):A99. https://doi.org/10.1136/archdischild-2012-301885.234.

45. Prieto-Centurion V, Markos MA, Ramey NI, et al. Interventions to reduce rehospitalizations after chronic obstructive pulmonary disease exacerbations: A systematic review. Ann Am Thorac Soc. 2014;11(3):417-24. https://doi.org/10.1513/AnnalsATS.201308-2540C.

46. Pedros C, Formiga F, Corbella X, Arnau J. Adverse drug reactions leading to urgent hospital admission in an elderly population: Prevalence and main features. Eur J Clin Pharmacol. 2016;72(2):219-26. https://doi.org/10.1007/ s00228-015-1974-0.

47. Al Hamid A, Ghaleb M, Aljadhey H, Aslanpour Z. A systematic review of hospitalization resulting from medicine-related problems in adult patients. Br J Clin Pharmacol. 2014;78(2):202-17. https://doi.org/10.1111/bcp.12293.

48. Wilbur K, Hazi H, El-Bedawi A. Drug-Related Hospital Visits and Admissions Associated with Laboratory or Physiologic Abnormalities-A SystematicReview. PLoS One. 2013;8(6) https://doi.org/10.1371/journal.pone.0066803.

49. Kongkaew C, Noyce PR, Ashcroft DM. Hospital Admissions Associated with Adverse Drug Reactions: A Systematic Review of Prospective Observational Studies. Ann Pharmacother. 2008;42(7):1017-25. https:// doi.org/10.1345/aph.1L037.

50. Lester D. Theories of attempted suicide: Should they differ from theories of completed suicide? Clin Neuropsychiatry. 2009;6(5):188-91. https://doi.org/ 10.1002/pds.

51. Howard RL, Avery AJ, Slavenburg S, et al. Which drugs cause preventable admissions to hospital? A systematic review. Br J Clin Pharmacol. 2007;63(2): 136-47. https://doi.org/10.1111/j.1365-2125.2006.02698.x.

52. Mozaffarian D, Benjamin E, Go A, et al. Heart Disease and Stroke Statistics2016 Update: A Report from the American Heart Association. Circulation. 2016;133(4):e38-360

53. Wier L, Elixhauser A, Pfuntner A, Au D. Overview of Hospitalizations among Patients with COPD, 2008: Statistical Brief \#106. Healthc Cost Util Proj Stat Briefs. 2011;February:1-11.

54. U.S. Department of Health \& Human Services. Asthma Hospital Inpatient Discharges. 2010. https://www.cdc.gov/asthma/most_recent_data.htm.

55. Tran D, Ohinmaa A, Thanh N, et al. The current and future financial burden of hospital admissions for heart failure in Canada: a cost analysis. Can Med Assoc J open. 2016;4(3):365-70. https://doi.org/10. 9778/cmajo.20150130.

56. Venkatesh AK, Dai Y, Ross JS, et al. Variation in U.S. Hospital Emergency Department Admission Rates by Clinical Condition. Med Care. 53(3):237-44. https://doi.org/10.1097/MLR.0000000000000261. Variation

57. Health and Social Care Information Centre. Hospital Episode Statistics, Admitted Patient Care - England, 2014-15. 2015. http://content.digital.nhs. uk/catalogue/PUB19124. Accessed 1 Aug 2017.

58. Hospital N, Medical A, Survey C. National Hospital Ambulatory Medical Care Survey : 2013 Emergency Department Summary Tables. 2013. 
59. Australian Institutes of Health and Welfare. Admitted patient care 2014-15: Australian hospital statistics. 2016. https://www.aihw.gov.au/reports/ hospitals/ahs-2014-15-admitted-patient-care/contents/table-of-contents . Accessed 1 Aug 2017.

60. Chin KL, Skiba M, Tonkin A, et al. The treatment gap in patients with chronic systolic heart failure: a systematic review of evidence-based prescribing in practice. Heart Fail Rev. 2016;21(6):1-23. https://doi.org/10. 1007/s10741-016-9575-2.

61. Price D, West D, Brusselle G, et al. Management of COPD in the UK primarycare setting: an analysis of real-life prescribing patterns. Int J Chron Obstruct Pulmon Dis. 2014. p. 889-905.

62. British Society for Heart Failure, NICOR H. British Society for Heart Failure National Heart Failure Audit. 2017.

63. Doran T, Kontopantelis E, Valderas JM, et al. Effect of financial incentives on incentivised and non-incentivised clinical activities: Iongitudinal analysis of data from the UK Quality and Outcomes Framework. BMJ. 2011;342:d3590. https://doi.org/10.1136/bmj.d3590.

64. Bennie M, Godman B, Bishop I, Campbell S. Multiple initiatives continue to enhance the prescribing efficiency for the proton pump inhibitors and statins in Scotland. Expert Rev Pharmacoeconomics Outcomes Res. 2012; 12(1):125-30.

65. Kendrick T, Stuart B, Newell C, Geraghty AWA, Moore M. Did NICE guidelines and the Quality Outcomes Framework change GP antidepressant prescribing in England? Observational study with time trend analyses 2003-2013. J Affect Disord. 2015;186:171-7. https://doi.org/10.1016/j.jad. 2015.06.052.

66. National Institute for Health and Care Excellence. Chronic heart failure in adults: management. Clinical guideline. 2014. nice.org.uk/guidance/cg108.

67. Task A, Members F, Ponikowski P, et al. 2016 ESC Guidelines for the diagnosis and treatment of acute and chronic heart failure The Task Force for the diagnosis and treatment of acute and chronic heart failure of the European Society of Cardiology (ESC) Developed with the special contribution; 2016. p. 2129-200. https://doi.org/10.1093/eurheartj/ehw128.

68. Grigorian L, Barge E, Bassante P. Heart failure in patients with preserved and deteriorated left ventricular ejection fraction. Heart. 2005;91:489-95. https:// doi.org/10.1136/hrt.2003.031922.

69. Redfield MM. Trends in Prevalence and Outcome of Heart Failure with Preserved Ejection Fraction; 2017. p. 251-9.

70. The world bank group. Population totals. 2017. http://data.worldbank.org/ indicator/SP.POP.TOTL.

71. Medicines and Healthcare products Regulatory Agency. Cox-2 Selective Inhibitors and Non-Steroidal Anti-Inflammatory Drugs' (NSAIDs): Cardiovascular Safety. 2015. https://www.gov.uk/government/publications/ cox-2-selective-inhibitors-and-non-steroidal-anti-inflammatory-drugs-nsaidscardiovascular-safety.

72. National Institute for Health and Care Excellence. Chronic obstructive pulmonary disease in over 16s: diagnosis and management. 2010. https:// www.nice.org.uk/guidance/cg101/resources/chronic-obstructive-pulmonarydisease-in-over-16s-diagnosis-and-management-pdf-35109323931589. Accessed 20 July 2008

73. National Institute for Health and Care Excellence. Psychosis and schizophrenia in adults: prevention and management. Clinical guideline [CG178]. 2014. https://www.nice.org.uk/guidance/cg178/chapter/1recommendations.

74. Payne R, Abel G, Guthrie B, Mercer S. The effect of physical multimorbidity, mental health conditions and socioeconomic deprivation on unplanned admissions to hospital: a retrospective cohort study. Can Med Assoc J. 2013; 185(5):E221-E228.

\section{Ready to submit your research? Choose BMC and benefit from:}

- fast, convenient online submission

- thorough peer review by experienced researchers in your field

- rapid publication on acceptance

- support for research data, including large and complex data types

- gold Open Access which fosters wider collaboration and increased citations

- maximum visibility for your research: over $100 \mathrm{M}$ website views per year

At BMC, research is always in progress.

Learn more biomedcentral.com/submissions 